\title{
CDS-1548 induces apoptosis in HeLa cells by activating caspase 3
}

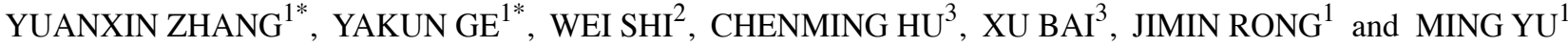 \\ ${ }^{1}$ College of Biology and Food Engineering, Jilin Institute of Chemical Technology, Jilin, Jilin 132022; \\ ${ }^{2}$ Key Laboratory for Molecular Enzymology and Engineering of The Ministry of Education, School of Life Science; \\ ${ }^{3}$ The Center for Combinatorial Chemistry and Drug Discovery, College of Pharmacy, Jilin University, \\ Changchun, Jilin 130012, P.R. China
}

Received September 5, 2018; Accepted May 17, 2019

DOI: $10.3892 / 01.2019 .10511$

\begin{abstract}
Cervical cancer continues to be a threat to female health globally. In the present study, the potential anticancer activity of 2-[2-hydroxyl-1-(4-methoxy phenyl) ethyl]-3-(4-benzyloxy phenyl) isoindolin-1-one (CDS-1548), was evaluated in HeLa cells. CDS-1548 is an organic small-molecule compound characterized by two chiral centers, with the nuclear parent $1 \mathrm{H}$-isoindolin-1-one. CDS-1548 administration significantly elevated the transcriptional activity of p53 and its downstream target genes in a dose-dependent manner. Additionally, CDS-1548 treatment increased the expression levels of p53 and mouse double minute 2 homolog, as well as inducing apoptosis in HeLa cells. Furthermore, CDS-1548 treatment downregulated the expression of B-cell lymphoma 2, upregulated Bcl-2 homologous antagonist killer, promoted the release of cytochrome $\mathrm{c}$ from mitochondria to cytoplasm, and activated the production of caspase 3 and 9 . Collectively, these results suggested that CDS-1548 inhibited HeLa cell proliferation by promoting $\mathrm{G}_{2} / \mathrm{M}$ cell cycle phase arrest and inducting of mitochondria-mediated apoptosis.
\end{abstract}

\section{Introduction}

Cervical cancer is a gynecological disease that continues to threaten the health of women globally. By integrating viral DNA into human chromosomal DNA and activating proto-oncogenes (or deactivating tumor suppressor genes), the Human papilloma virus (HPV) is one of the primary causes of cervical cancer (80-90\%) (1). Currently, >100 HPV variants

Correspondence to: Professor Wei Shi, Key Laboratory for Molecular Enzymology and Engineering of The Ministry of Education, School of Life Science, Jilin University, 2699 Qianjin Street, Changchun, Jilin 130012, P.R. China

E-mail: shiw@jlu.edu.cn

\section{${ }^{*}$ Contributed equally}

Key words: small-molecule inhibitor, HeLa, p53, $\mathrm{G}_{2} / \mathrm{M}$ arrest, apoptosis have been identified, though few are carcinogenic (2). HPV types 16 and 18, classified as high-risk HPVs, are able to promote the progression of premalignant lesions, which unless treated, ultimately results in the development of cancer (3). Of all cervical cancer cases, $\sim 70 \%$ have been associated with HPV 16 and 18 (4); furthermore, high-risk HPVs secrete early protein 6 that forms a complex with p53, resulting in its ubiquitination and subsequent degradation (5).

p53 is a powerful transcription factor that prevents the malignant transformation of cells, and as such is frequently inactivated following viral infection $(6,7)$. Various stress signals, including oncogene activation, DNA damage and hypoxia, improve the stability of wild-type p53. Alterations in p53 expression level are associated with the transcription of specific p53-responsive gene, including p21, Bcl-2-associated $\mathrm{X}$ protein (Bax), p53 upregulated modulator of apoptosis (PUMA) and growth arrest and DNA damage-inducible 45, which are involved in p53-induced cell cycle arrest, metabolism, DNA repair, apoptosis and senescence $(8,9)$. Previous investigations have revealed that mutations in $\mathrm{p} 53$ are present in $~ 50 \%$ human cancers (10). Under normal conditions, p53 is tightly regulated by the mouse double minute 2 homolog (Mdm2) protein via a self-regulating feedback loop $(11,12)$. p53 is able to increase the expression level of Mdm2, which conversely inhibits p53 in three ways: i) Mdm2 binds to the transactivation domain of p53 and subsequently inhibits transcriptional activity; ii) Mdm2 blocks the nuclear export of p53; or iii) Mdm2 may function as an E3 ubiquitin protein ligase, targeting p53 for ubiquitination and degradation (13). Furthermore, the overexpression of the Mdm2 gene may result in loss of p53 function in numerous types of malignant tumor (14). Therefore, interrupting the p53-Mdm2 interaction (or Mdm2 itself) with small-molecule inhibitors may reactivate p53 and inhibit tumor growth $(15,16)$; the development of nutlin-3 provides important proof-of-concept for the design of small-molecule inhibitors of Mdm2 (17).

The present study introduced the organic small-molecule compound 2-[2-hydroxyl-1-(4-methoxy phenyl) ethyl]-3-(4-benzyloxy phenyl) isoindolin-1-one (CDS-1548), which altered the activity of cervical cancer cell lines by promoting the accumulation of p53 and inducing apoptosis. In the present study, the method by which CDS-1548 activates p53 and inhibits tumor cell viability (by eliciting apoptosis and cell cycle arrest) was investigated. 


\section{Materials and methods}

Cell culture and reagents. The human cervical cancer cell line HeLa was purchased from the Chinese Academy of Sciences Cell Bank (Shanghai, China) and maintained in Dulbecco's modified Eagle's medium (DMEM; Corning, Inc.) with $10 \%$ fetal bovine serum (cat. no., 626216; Omega Bio-Tek, Inc.), 2 mmol/l L-glutamine (Sigma-Aldrich; Merck $\mathrm{KGaA}$ ), $100 \mathrm{IU} / \mathrm{ml}$ penicillin (Sigma, Shanghai) and $100 \mu \mathrm{g} / \mathrm{ml}$ streptomycin (Sigma-Aldrich; Merck KGaA). The following antibodies were purchased from Santa Cruz Biotechnology, Inc.: Anti-caspase 3 (cat. no. sc-56053), anti-caspase 8 (cat. no. sc-81656), anti-caspase 9 (cat. no. sc-133109), anti-cleaved poly (ADP-ribose) polymerase 1 (PARP-1; cat. no. sc-56196), anti-p53 (cat. no. sc-47698), anti-p21 (cat. no. sc-71811), anti-Mdm2 (cat. no. sc-5304), anti-cytochrome c (cat. no. sc-13560), anti-cyclin B1 (cat. no. sc-245), anti-cyclin-dependent kinase 1/2 (CDK1/2; cat. no. sc-53219), anti-checkpoint kinase 1 (CHK1; cat. no. sc-56288), anti-checkpoint 2 (CHK2; cat. no. sc-136251), anti-M-phase phosphatase 3 (CDC25C; cat. no. sc-327), H2AX, H2A histone family, member X (H2AX; cat. no. sc-54606), anti-p-ataxia telangiectasia and Rad3-related protein (ATR; cat. no. sc-515173), anti-B-cell lymphoma 2 (Bcl-2; cat. no. sc-7382), anti-Bcl-2 homologous antagonist killer (BAK; cat. no. sc-517390), anti-BAX (cat. no. sc-7480), anti-PUMA (cat. no. sc-374223) and anti- $\beta$-actin (cat. no. sc-8432). Anti-phosphorylated (p)-CHK1 (cat. no. 12302) and anti-p-CHK2 (cat. no. 2197) were obtained from Cell Signaling Technology. Inc., and anti- $\gamma-\mathrm{H} 2 \mathrm{AX}$ histone family (cat. no. ab26350) was purchased from Abcam. M-MLV Reverse Transcriptase (cat. no. 28025013) was obtained from Thermo Fisher Scientific, Inc. Propidium iodide (PI), 4',6-diamidino-2-phenylindole (DAPI), 3-(4,5-dimethyl-2-thi azolyl)-2,5-diphenyl-2H-tetrazolium bromide (MTT), and all other chemical reagents were obtained from Sigma-Aldrich (Merck KGaA). The fluorescein isothiocyanate (FITC) Annexin V Apoptosis Detection Kit I was purchased from Bioteke Corporation. Caspase 3,8 and 9 activity assay kits were obtained from BestBio. Cell Mitochondria Isolation kit (cat. no. c3601) was purchased from Beyotime Institute of Biotechnology. CDS-1548 was synthesized by the Center for Combinatorial Chemistry and Drug Discovery of Jilin University (Changchun, China) according to a previously reported method $(18,19)$.

Cell viability assay. An MTT assay was conducted to evaluate the effects of CDS-1548 on cell viability. Briefly, $5 \times 10^{3}$ cells/well were seeded into 96-well plates and incubated in serum-free DMEM for $24 \mathrm{~h}$ at $37^{\circ} \mathrm{C}$. The cells were washed with phosphate-buffered saline (PBS, pH 7.0) and treated at $37^{\circ} \mathrm{C}$ with various concentrations of CDS-1548 $(0.14,0.37,1.1$, $3.3,11,33$ and $100 \mu \mathrm{M}$, to a final volume of $100 \mu \mathrm{l} /$ well) for 12,24 and $48 \mathrm{~h}$. Following treatment, $20 \mu \mathrm{l}$ MTT solution was added and the cells were incubated for an additional $3 \mathrm{~h}$ at $37^{\circ} \mathrm{C}$. The culture medium was subsequently removed and $150 \mu \mathrm{l}$ dimethyl sulfoxide (DMSO) was added to dissolve the formazan crystals. The absorbance of was assessed at $495 \mathrm{~nm}$ using a microplate reader and equated to the number of viable cells.

Nuclear staining. To examine the condensation and fragmentation of cellular nuclei, $5 \times 10^{4}$ cells/well were seeded in to 24-well plates and incubated for $24 \mathrm{~h}$; the medium was then replaced with equal quantities of DMEM or DMEM $+2 \mu \mathrm{M}$ CDS-1548. Following a further 24-h incubation at $37^{\circ} \mathrm{C}$, the cells were washed with PBS and stained with DAPI $(2.5 \mu \mathrm{g} / \mathrm{ml})$ for $5 \mathrm{~min}$ at room temperature. The morphology of the nuclei was determined by fluorescence microscopy (magnification, $\mathrm{x} 10$ ).

Reverse transcription-quantitative polymerase chain reaction $(R T-q P C R)$. Total RNA was extracted from cells using TRIzol $^{\circledR}$ reagent (Thermo Fisher Scientific, Inc.) and $1 \mu \mathrm{g}$ total RNA was used as a template for reverse transcription using M-MLV reverse transcriptase (Thermo Fisher Scientific, Inc.), according to previous methods $(20,21)$. The synthesized cDNA was subsequently amplified by qPCR using SYBR ${ }^{\mathrm{TM}}$ Green PCR Master Mix (Thermo Fisher Scientific, Inc.) in 7500 Fast Real-Time PCR System, according to the manufacturer's protocols. The following thermocycling conditions: Denaturation $\left(94^{\circ} \mathrm{C}\right.$ for $\left.30 \mathrm{sec}\right)$, annealing $\left(55^{\circ} \mathrm{C}\right.$ for $\left.30 \mathrm{sec}\right)$ and extension $\left(72^{\circ} \mathrm{C}\right.$ for $\left.1 \mathrm{~min}\right)$ for 30 cycles. The primers used were as follows: $\beta$-actin forward, 5 -TCTGGCACCACACCT TCTACAATG-3', and reverse, 5'-GGATAGCACAGCCTG GATAGCAA-3'; p53 forward, 5'-GGCTCTGACTGTACC ACCATCCA-3', and reverse, 5'-GGCACAAACACGCAC CTCAAAG-3'; p21 forward, 5'-GGAAGACCATGTGGACCT GT-3', and reverse, 5'-GGCGTTTGGAGTGGTAGAAA-3'; and PUMA forward, 5'-TAGAGAGAGCGACGTGAC-3', and reverse, 5'-CGGTATCTACAGCAGCGCAT-3. mRNA levels were quantified using the $2^{-\Delta \Delta C q}$ method (20) and normalized to the internal reference gene $\beta$-actin. The experiments were repeated at least three times.

Cell cycle status and apoptosis assay. Early apoptotic cells were characterized by the translocation of phosphatidylserine to the outer surface of the cell membrane (22). Annexin V/PI staining was used to detect the number of apoptotic cells, according to the manufacturer's protocol. Briefly, $4 \times 10^{5}$ cells/well were incubated overnight in 6-well plates, and treated with 2,5 , or $10 \mu \mathrm{M}$ CDS-1548 prior to a further 24,48 or $72-\mathrm{h}$ incubation at $37^{\circ} \mathrm{C}$. Following treatment, the cells were harvested in $15 \mathrm{ml}$ tubes by trypsinization, and the medium was removed by centrifugation at $3,000 \mathrm{xg}$ for $5 \mathrm{~min}$ at $4^{\circ} \mathrm{C}$. For the apoptotic assay, cells were washed twice in ice-cold PBS, aspirated and resuspended in binding buffer with FITC-annexin V and PI at room temperature for 15 min (in the dark). Subsequently, cells were resuspended in binding buffer and flow cytometricaly analyzed using the Beckman Flow Cytometry Analyzer (Beckman CytoFLEX; Beckman Coulter, Inc.,). For cell cycle analysis, following the aforementioned CDS-1548 treatment, cells were rinsed in PBS, resuspended in $5 \mathrm{ml}$ PI solution $(25 \mu \mathrm{g} / \mathrm{ml}$ RNase A, $50 \mu \mathrm{g} / \mathrm{ml} \mathrm{PI}$ ) and incubated at $37^{\circ} \mathrm{C}$ for $30 \mathrm{~min}$ in the dark. The cell cycle distribution was determined using the Beckman Flow Cytometry Analyzer and the data were statistically analyzed using SPSS 19.0 software (IBM Corp.).

Western blotting. Following treatment with CDS-1548, the cells were lysed at $4^{\circ} \mathrm{C}$ using ice-cold lysis buffer [50 mmol/1 Tris (pH 8.0), $150 \mathrm{mmol} / 1 \mathrm{NaCl}, 0.1 \%$ SDS, $1 \%$ NP40 and $0.5 \%$ sodium deoxycholate] supplemented with 
$\mathbf{A}$

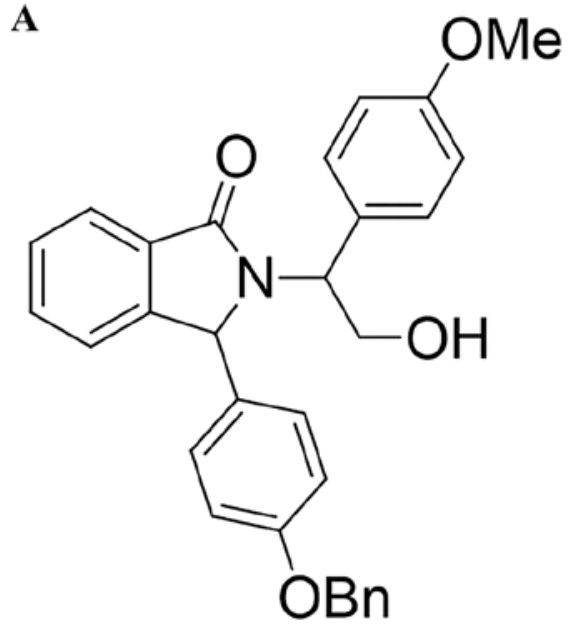

Me: methyl group Bn: benzyl group
B

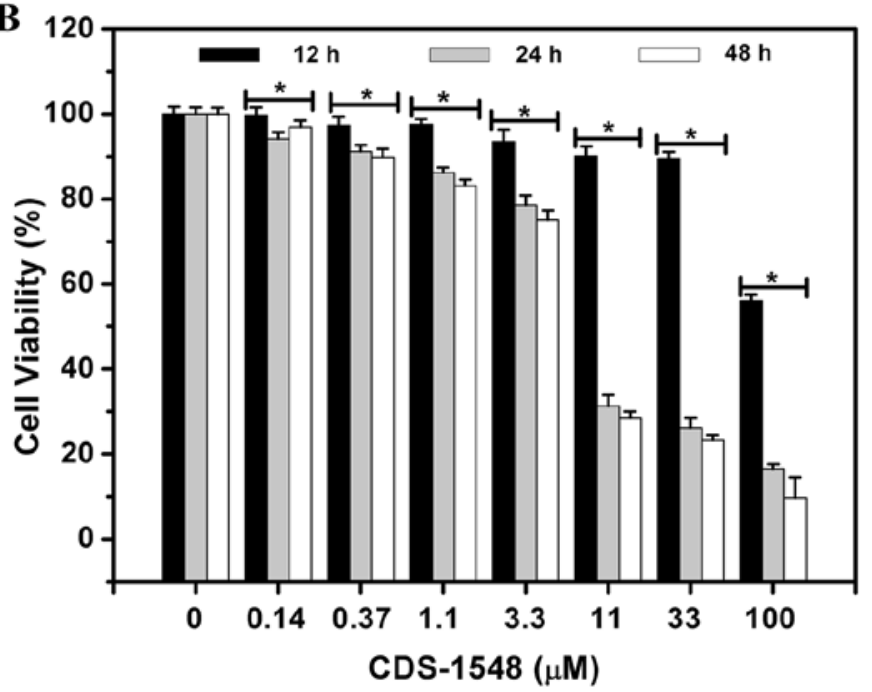

Figure 1. Inhibitory effect of CDS-1548 on the viability of human cervical cancer cells. (A) Molecular structure of CDS-1548. (B) HeLa cells were plated at a density of $5 \times 10^{3}$ cells/well and incubated with of $0.14,0.37,1.1,3.3,11,33$ or $100 \mu \mathrm{M}$ CDS-1548 for 12,24 or 48 h. Cell viability was assessed using an MTT assay. "P<0.05 vs. control. CDS-1548, 2-[2-hydroxyl-1-(4-methoxy phenyl) ethyl]-3-(4-benzyloxy phenyl) isoindolin-1-one.

protease/phosphatase inhibitors (1\% Cocktail and $1 \mathrm{mmol} / \mathrm{l}$ phenylmethylsulfonyl fluoride). The lysates were centrifuged at $10,000 \mathrm{x} \mathrm{g}$ for $5 \mathrm{~min}$ at $4^{\circ} \mathrm{C}$, and the supernatant was collected. Protein quantification was performed using a Bradford assay kit and $40 \mu \mathrm{g}$ protein/lane was separated by SDS-PAGE (10\% gel). The proteins were transferred to polyvinylidene fluoride membranes (EMD Millipore) and blocked using TBS with $5 \%$ fat-free milk and $0.1 \%$ tween-20 for $1 \mathrm{~h}$ at room temperature. The membranes were washed twice in TBST and incubated with primary antibodies (1:200) overnight at $4^{\circ} \mathrm{C}$. The membranes were rinsed three times with ice-cold PBS and then incubated with peroxidase-conjugated secondary antibodies $(1: 2,000)$ for $2 \mathrm{~h}$ at room temperature. The protein bands were visualized using the BeyoECL Star kit (Beyotime Institute of Biotechnology).

Mitochondria and cytosol extraction. Briefly, cells $\left(8 \times 10^{6}\right)$ were seeded in a T75 flask and then incubated overnight at $37^{\circ} \mathrm{C}$. After $24-\mathrm{h}$ treatment with CDS-1548 $(2,5$ and $10 \mu \mathrm{M})$, cells were scraped from the plate in PBS and harvested by centrifugation at $500 \mathrm{x}$ g for $5 \mathrm{~min}$ at $4^{\circ} \mathrm{C}$. The cell pellets were resuspended in extraction buffer from the Cell Mitochondria Isolation kit $[20 \mathrm{mmol} / 1 \mathrm{HEPES}(\mathrm{pH} 7.5), 1.5 \mathrm{mmol} / \mathrm{l}$ $\mathrm{MgCl}_{2}, 10 \mathrm{mmol} / 1 \mathrm{KCl}, 1 \mathrm{mmol} / 1$ EDTA, $1 \mathrm{mmol} / 1$ EGTA, $1 \mathrm{mmol} / 1 \mathrm{DTT}, 0.1 \mathrm{mmol} / 1$ phenylmethylsulfonyl fluoride, and $250 \mathrm{mmol} / 1$ sucrose], and homogenized using a microhomogenizer. The homogenates were subsequently centrifuged at $750 \mathrm{x} \mathrm{g}$ for $10 \mathrm{~min}$ at $4^{\circ} \mathrm{C}$. To isolate mitochondrial extracts, the supernatants were re-centrifuged at $10,000 \mathrm{x}$ for $15 \mathrm{~min}$ at $4^{\circ} \mathrm{C}$, and the precipitate (mitochondria protein extract) and the supernatant (cytoplasmic fractions.) were retrieved.

Determination of caspase activity. Caspase-3, 8 and 9 activity were determined using caspase-3/8/9 activity kits according to the manufacturer's protocols. Briefly, following treatment with CDS-1548, the cells were scraped from the culture plates in PBS (0.01 M, pH 7.4) and centrifuged at 10,000 x g at $4^{\circ} \mathrm{C}$. The cell pellets were lysed in $100 \mu \mathrm{l}$ lysis buffer and the resulting suspension was centrifuged at $10,000 \mathrm{xg}$ for $10 \mathrm{~min}$ at $4^{\circ} \mathrm{C}$. An equal amount of supernatant was incubated with the corresponding substrates in reaction buffer containing dithiothreitol, and the absorbance at $405 \mathrm{~nm}$ was determined using a microplate reader.

Statistical analysis. All quantitative data are expressed as the mean \pm standard deviation of three independent experiments. Statistical differences were evaluated using analysis of variance and the Least Significant Difference post hoc test. SPSS 19.0 (SPSS, Inc., IL, USA) was used for statistical analysis and $\mathrm{P}<0.05$ was considered to indicate a statistically significant difference.

\section{Results}

Inhibitory effects of CDS-1548 on HeLa cells. To assess the inhibitory effects of CDS-1548 on HeLa cells (Fig. 1A), a concentration-escalation experiment was performed (Fig. 1B). CDS-1548 reduced cell viability in a dose- and time-dependent manner. The MTT assay revealed that the half maximal inhibitory concentration $\left(\mathrm{IC}_{50}\right)$ of CDS-1548 in HeLa cells was markedly reduced following increasing treatment durations. The $\mathrm{IC}_{50}$ at 12,24 and $48 \mathrm{~h}$ were $100.0,4.3$ and $4.0 \mu \mathrm{M}$, respectively. Notably, at $11 \mu \mathrm{M}, \mathrm{CDS}-1548$ significantly enhanced cell cytotoxicity following 24 - and 48-h of treatment, suggesting that this was the optimum concentration in HeLa cells. However, significant differences were not observed between the 24- and 48-treatments due to the cycling time of the HeLa cell line.

CDS-1548 induces $G_{2} / M$ arrest in HeLa cells. To determine whether CDS-1548 caused cell-cycle arrest, a flow cytometric cell cycle assay was performed using HeLa cells following $24 \mathrm{~h}$ of treatment with $0,2,5$, or $10 \mu \mathrm{M}$ CDS-1548. A significantly increased percentage of $\mathrm{G}_{2} / \mathrm{M}$-phase cells was observed from $25.115 \%(0 \mu \mathrm{M})$ to $38.65 \%(2 \mu \mathrm{M}), 73.03 \%(5 \mu \mathrm{M})$ or $89.62 \%$ (10 $\mu \mathrm{M}$ CDS-1548; Fig. 2A). To further elucidate the 
A
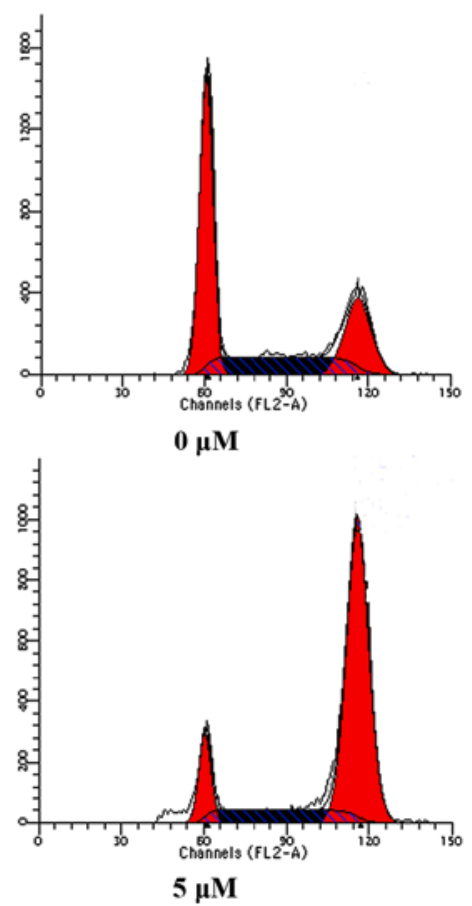
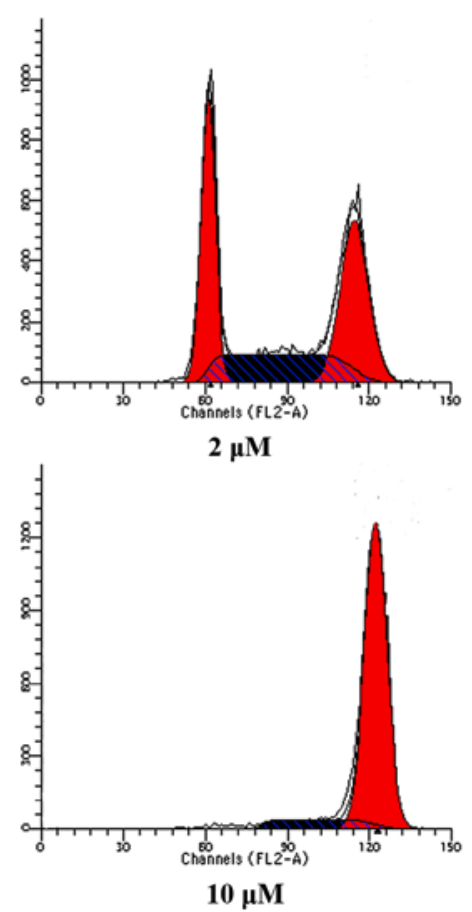

B

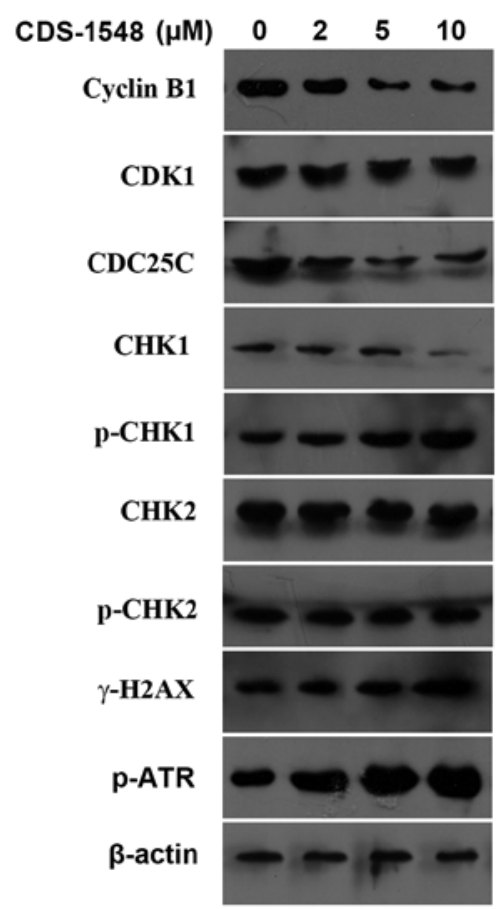

Figure 2. CDS-1548 treatment induces cell cycle arrest at the $\mathrm{G}_{2} / \mathrm{M}$ phase. (A) HeLa cells were treated with 2,5 or $10 \mu \mathrm{M}$ CDS-1548 for 24 h, stained with propidium iodide, and the DNA content analyzed by flow cytometry. N=3. (B) HeLa cells were treated with 2,5 or $10 \mu \mathrm{M}$ CDS-1548 for 24 h. The expression levels of proteins associated with the cell cycle were detected by western blotting. CDS-1548, 2-[2-hydroxyl-1-(4-methoxy phenyl) ethyl]-3-(4-benzyloxy phenyl) isoindolin-1-one; CKD1, cyclin dependent kinase 1; CHK1, checkpoint kinase 1; CHK2, checkpoint kinase 2; CDC25C, M-phase phosphatase 3; H2AX, H2A histone family, member X; ATR, ataxia telangiectasia and Rad3-related protein; p-, phosphorylated.

potential molecular mechanism underlying CDS-1548-induced cell-cycle arrest, the expression levels of proteins associated with $\mathrm{G}_{2} / \mathrm{M}$ phase progression were determined. The results indicated that CDS-1548 downregulated the expression level of cyclin B1 in a dose-dependent manner, upregulated the expression levels of p-CHK 1 and decreased the levels of CDC25C compared with the control-treated cells. However, CDS-1548 did not alter the expression levels of CHK2 or its phosphorylation (Fig. 2B). Alterations in the expression levels of p-ATR and the histone $\gamma$-H2AX, DNA-damage markers associated with CHK1, were also determined. CDS-1548 treatment increased the level of $\gamma-\mathrm{H} 2 \mathrm{AX}$ expression and ATR phosphorylation. These data suggested that CDS-1548 induced cell cycle arrest at the $\mathrm{G}_{2} / \mathrm{M}$-phase via DNA-damage checkpoint pathways.

CDS-1548 induces p53-dependent apoptosis in human cervical cancer cells. The present study investigated whether the inhibitory effect of CDS-1548 on HeLa cells also induced cell death. As illustrated in Fig. 3A, chromatin condensation and apoptotic bodies were observed in the nuclei subsequent to treatment with CDS-1548. Furthermore, flow cytometric analysis indicated that CDS-1548 induced the accumulation of early apoptotic cells (annexin V+/PI-), suggesting that apoptosis in HeLa cells was dose- and time-dependent (Fig. 3B). After 24-h treatment with CDS-1548 $(2,5$ and $10 \mu \mathrm{M})$ the percentages of early apoptotic cells were $2.82,9.21$ and $14.7 \%$, and the percentages of necrotic cells (annexin V+/PI+) were $3.69,2.95$ and $4.16 \%$ respectively. Compared with $24-\mathrm{h}$ CDS-1548 treatment, the proportions of early apoptotic cells in the 48-h treatment group was significantly increased, to 3.33,
35.51 and $51.32 \%$; the percentages of necrotic cells were 0.89 , 3.05 and $6.41 \%$ for 2,5 , and $10 \mu \mathrm{M}$ CDS-1548, respectively. These results indicated that the inhibitory effects observed in response to CDS-1548 were primarily associated with the induction of apoptosis, and not necrosis in HeLa cells.

To confirm the effect of CDS-1548 on p53 activation, the expression levels of p53, p-p53 and the downstream target genes of p53 were determined. Fig. 3C and D illustrate that the mRNA and protein expression levels of p53, p21 and PUMA were increased in a dose-dependent manner in HeLa cells, compared with control treated cells. Furthermore, the upregulation of Mdm2 protein expression was observed. These results demonstrated that p53 accumulated in HeLa cells following CDS-1548 treatment, resulting in an increase in the expression levels of p21, Mdm2 and PUMA in a p53-associated manner.

CDS-1548 triggers apoptosis by activating the mitochondriamediated pathway. Previous investigations have demonstrated that p53-mediated apoptotic cell death is associated with the intrinsic mitochondrial pathway $(23,24)$. The present study investigated the expression of PARP and pro-caspase-3 (an effector caspase) to determine whether cell death was apoptotic in nature. As presented in Fig. 4A, CDS-1548 resulted in the cleavage of PARP and decreased the expression levels of pro-caspase 9 and 3 in a dose-dependent manner; the expression level of pro-caspase 8 was not altered. These results suggested that CDS-1548 induced apoptotic cell death. Furthermore, CDS-1548 treatment downregulated Bcl-2 expression levels and upregulated those of BAK, but not $\mathrm{BAX}$, resulting in the release of cytochrome $\mathrm{c}$ into the cytosol 
A
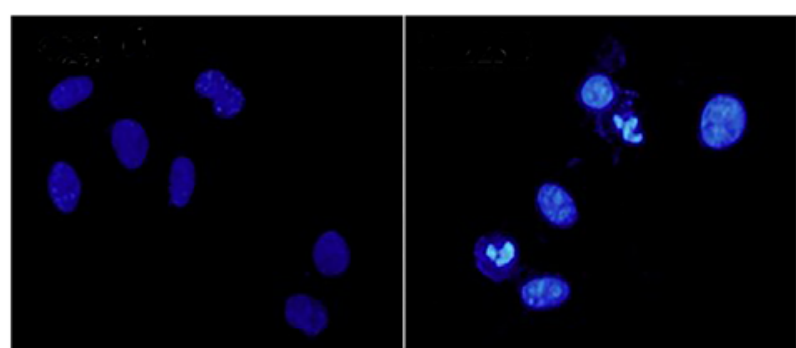

B
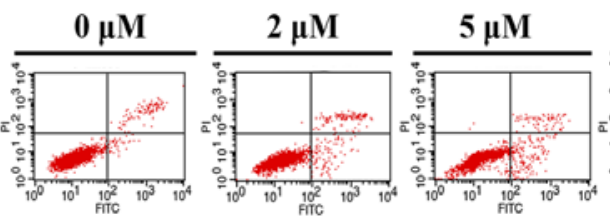

$10 \mu \mathrm{M}$
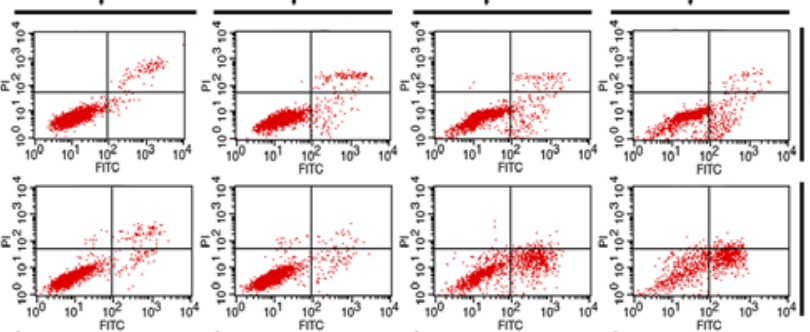

$24 \mathrm{~h}$
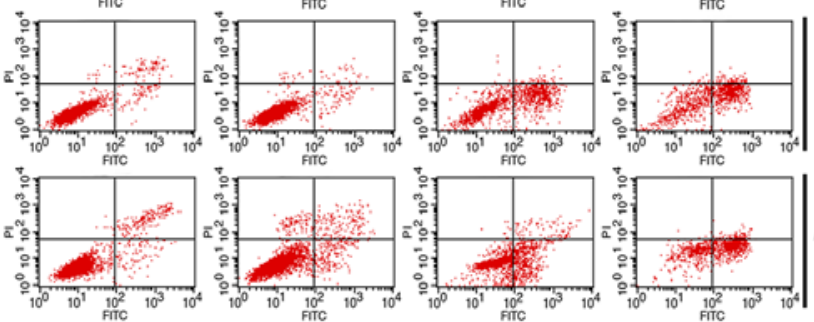

C
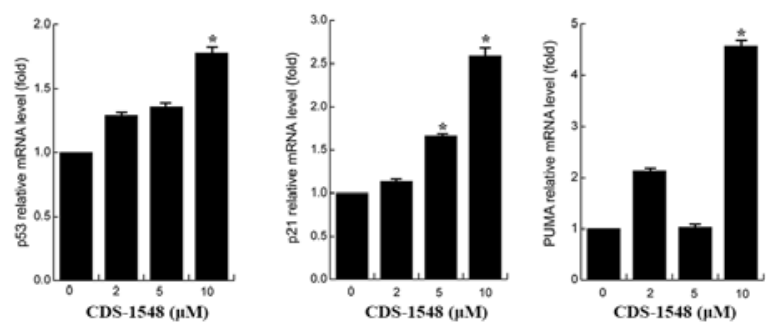

D

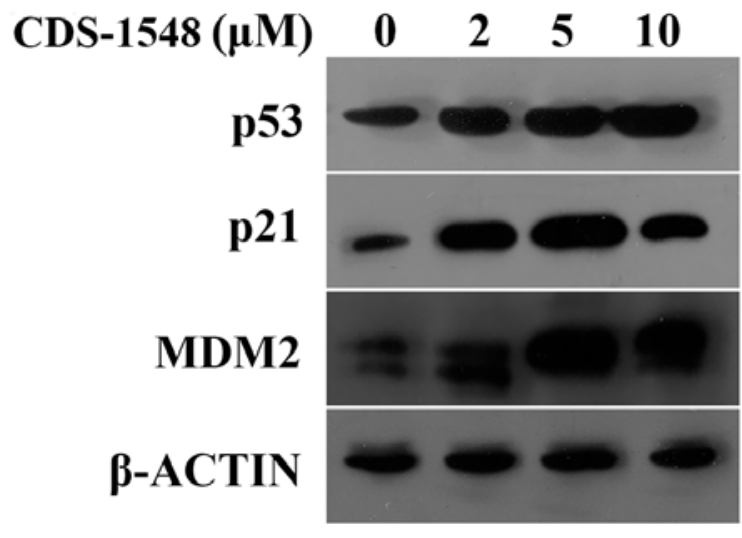

Figure 3. CDS-1548 activates p53 and induces apoptosis in HeLa cells. (A) Cells were treated with $5 \mu \mathrm{M}$ CDS-1548 for $24 \mathrm{~h}$, fixed and stained using DAPI The morphology of the nuclei was observed under a fluorescent microscope using a blue filter. (B) HeLa cells were treated with 2, 5 or $10 \mu \mathrm{M}$ CDS-1548 for 24,48 or $72 \mathrm{~h}$, and the apoptotic index was assessed using flow cytometry. The administration of CDS-1548 markedly enhanced the number of apoptotic cells, compared with the DMSO control. (C) HeLa cells were treated with 2, 5 or $10 \mu \mathrm{M}$ CDS-1548 for $12 \mathrm{~h}$, and p53, p21 and PUMA mRNA expression levels were determined using reverse transcription-quantitative PCR. ${ }^{*} \mathrm{P}<0.05$ vs. control. (D) HeLa cells were treated with 2,5 or $10 \mu \mathrm{M}$ CDS-1548 for $24 \mathrm{~h}$, and protein expression levels of p53, p21 and Mdm2 was determined by western blotting. CDS-1548, 2-[2-hydroxyl-1-(4-methoxy phenyl) ethyl]-3-(4-benzyloxy phenyl) isoindolin-1-one; Mdm2, mouse double minute 2 homolog; PUMA, p53 upregulated modulator of apoptosis.

A

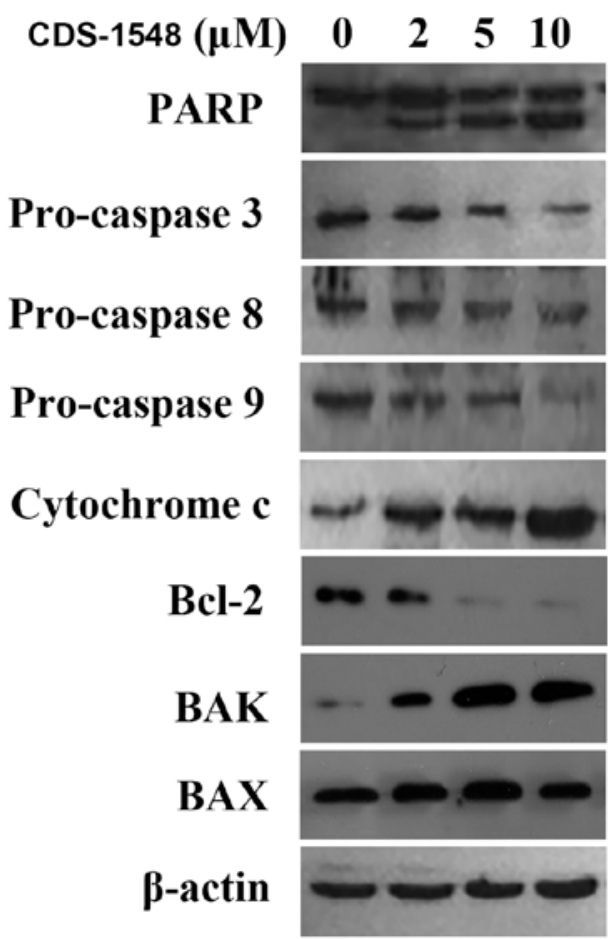

B

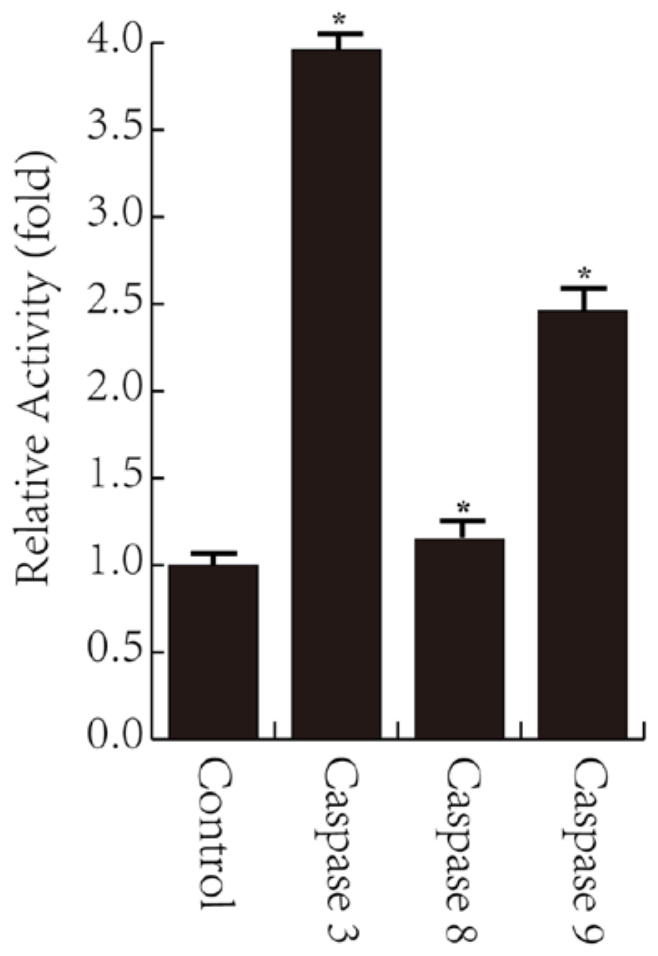

Figure 4. CDS-1548 triggers mitochondria-mediated apoptosis in HeLa cells. (A) Cells were incubated with 2, 5 or $10 \mu \mathrm{M}$ CDS-1548 for $24 \mathrm{~h}$ and equal amounts of cell lysate or mitochondria and cytoplasm lysates were resolved using SDS-PAGE for western blotting. (B) Cells were incubated with $10 \mu \mathrm{M}$ CDS-1548 for $24 \mathrm{~h}$. Equal amounts of cell lysate were analyzed for caspase 3, 8 and 9 activity; DMSO treatment was used as the control. Concentrations of the fluorescent products were subsequently determined. Results are presented as the mean \pm standard deviation of triplicate experiments. Significance was determined using the Student's t-test; "P<0.05 vs. control. CDS-1548, 2-[2-hydroxyl-1-(4-methoxy phenyl) ethyl]-3-(4-benzyloxy phenyl) isoindolin-1-one; PARP, poly ADP-ribose polymerase; Bcl-2, B-cell lymphoma 2; BAK, Bcl-2 homologous antagonist killer; BAX, Bcl-2-associated X protein. 
of HeLa cells. The caspase activity assay further indicated an increase in caspase 3 and 9 activity following CDS-1548 treatment, while caspase 8 activity remained unaltered (Fig. 4B). These results implied that CDS-1548 treatment inhibited Bcl-2 expression, but promoted BAK expression and cytochrome $\mathrm{c}$ release, inducing apoptosis via the mitochondria-mediated signaling pathway.

\section{Discussion}

Cervical cancer is an important threat to female health globally (25). Currently, regular screening and vaccination are effective means of preventing cervical cancer (26-29), though these methods are expensive and may not be affordable in developing countries (30). Chemotherapeutic treatments, although effective in a proportion of patients, are not completely curative and are accompanied by severe side effects (31). As an alternative approach, small molecule inhibitors that destroy cancerous cells with less toxic effects on normal cells may be beneficial (32). In previous years, potent, selective and efficacious small-molecule inhibitors have been successfully developed, and a number of these compounds have been advanced into clinical trials for the treatment of human cancers (33).

In the present study, the anticancer effect of CDS-1548 on HeLa cells was evaluated. CDS-1548 is characterized by two chiral centers, with $1 \mathrm{H}$-isoindolin-1-one as a nuclear parent. The results of the present study revealed that CDS-1548 treatment induced the activation of p53 and elevated the mRNA and protein expression levels of p53-targeted genes. Additionally, p21 may suppress CDK1 and cyclin B1 expression by inhibiting either CDK activity or impeding the formation of the CDK-cyclin B1 complex, thereby resulting in cell cycle arrest at the $\mathrm{G}_{2} / \mathrm{M}$ phase (34). Furthermore, the upregulated expression level of PUMA, an important regulatory factor of p53-mediated apoptosis (35), was observed. It was hypothesized that CDS-1548-induced p53 activation and elevated expression levels of p21 and PUMA served important roles in the promotion of $\mathrm{G}_{2 /} \mathrm{M}$ cell cycle arrest and apoptosis. The inhibition of Bcl-2 expression, the upregulation of BAK, the release of cytochrome $\mathrm{c}$ and the activation of caspase 3 and caspase 9 are considered to be markers of early-stage apoptosis; however, the potential function of CDS-1548 as an inhibitor of $\mathrm{p} 53$ requires further investigation by experimentation with alternative cell lines and in vivo studies.

The proliferation of cancer cells depends on a defect or dysfunction at the $G_{1}$ checkpoint, and subsequent entry into the $\mathrm{S}$ and $\mathrm{G}_{2}$ phases, where DNA damage repair is initiated (36). Therefore, cancer cells in the $\mathrm{G}_{2} / \mathrm{M}$ phase are sensitive to the cytotoxic effects of chemotherapeutic drugs. More importantly, the activation of p53 promotes apoptosis upon $\mathrm{G}_{2} / \mathrm{M}$ phase arrest in response to DNA damage (37). The results of the present study indicated that CDS-1548 induced cell cycle arrest at the $\mathrm{G}_{2} / \mathrm{M}$ phase, which was accompanied by the downregulation of cyclin $\mathrm{B} 1, \mathrm{CDK} 1$ and $\mathrm{CDC} 25 \mathrm{C}$. Additionally, the phosphorylation of $\mathrm{CHK} 1$ and the upregulation of ATR expression (involved in the DNA-damage response) were observed. Of note, there were no observed changes in $\mathrm{CHK} 2$ protein expression level in HeLa cells. Subsequently, it was confirmed that CDS-1548 treatment significantly induced the phosphorylation of ATR and $\gamma-\mathrm{H} 2 \mathrm{AX}$ in HeLa cells, collectively suggesting that CDS-1548 induced p53-dependent apoptosis by promoting $\mathrm{G}_{2} / \mathrm{M}$ phase arrest.

Further investigation is required to address the potential molecular mechanisms involved in CDS-1548-mediated p53 activation. Specifically, the regulatory action of CDS-1548 on Mdm2 and p53 is an important feedback loop that requires further clarification through in vitro and in vivo anti-tumor activity assays.

In conclusion, the present study demonstrated that the novel small-molecule inhibitor CDS-1548 possessed cytotoxicity against cancer cells. Furthermore, CDS-1548 triggered apoptosis via p53 accumulation and cell cycle arrest at the $\mathrm{G}_{2} / \mathrm{M}$ phase, indicating that the use of small-molecule inhibitors that target p53 may be a potential strategy for the treatment of cervical cancer.

\section{Acknowledgements}

Not applicable.

\section{Funding}

The present study was supported by grants from the Special Foundation for Industry Innovation of Development and Reform Commission of Jilin (grant no. 2018C049-4), the Foundation of Education Department of Jilin Province (grant no. 2016133), the Youth Foundation of Jilin Science and Technology Bureau (grant no. 20166026, 201750259) and the Major Programs of the Jilin Institute of Chemical Technology (grant no. 20180101).

\section{Availability of data and materials}

All data generated or analyzed during the present study are included in this published article.

\section{Authors' contributions}

YZ, XB and WS conceived and designed the experiments. YZ, $\mathrm{CH}$ and YG performed the experiments. JR and MY conducted the data analysis, and $\mathrm{YZ}$ produced the manuscript.

\section{Ethics approval and consent to participate}

Not applicable.

\section{Patient consent for publication}

Not applicable.

\section{Competing interests}

The authors declare that they have no competing interests.

\section{References}

1. Walboomers JM, Jacobs MV, Manos MM, Bosch FX, Kummer JA, Shah KV, Snijders PJ, Peto J, Meijer CJ and Muñoz N: Human papillomavirus is a necessary cause of invasive cervical cancer worldwide. J Pathol 189: 12-19, 1999. 
2. Bzhalava D, Eklund C and Dillner J: International standardization and classification of human papillomavirus types. Virology 476 : 341-344, 2015.

3. Kavanagh K, Pollock KG, Potts A, Love J, Cuschieri K, Cubie H, Robertson $\mathrm{C}$ and Donaghy $\mathrm{M}$ : Introduction and sustained high coverage of the HPV bivalent vaccine leads to a reduction in prevalence of HPV 16/18 and closely related HPV types. Br J Cancer 110: 2804-2811, 2014.

4. Schiffman M, Castle PE, Jeronimo J, Rodriguez AC and Wacholder S: Human papillomavirus and cervical cancer. Lancet 370: 890-907, 2007.

5. Scheffner M: Ubiquitin, E6-AP, and their role in p53 inactivation. Pharmacol Ther 78: 129-139, 1998.

6. Hollstein M, Sidransky D, Vogelstein B and Harris CC: p53 mutations in human cancers. Science 253: 49-53, 1991.

7. Oliner JD, Kinzler KW, Meltzer PS, George DL and Vogelstein B Amplification of a gene encoding a p53-associated protein in human sarcomas. Nature 358: 80-83, 1992.

8. Bates S and Vousden KH: Mechanisms of p53-mediated apoptosis. Cell Mol Life Sci 55: 28-37, 1999.

9. Khoo KH, Verma CS and Lane DP: Drugging the p53 pathway: Understanding the route to clinical efficacy. Nat Rev Drug Discov 13: 217-236, 2014

10. Soussi T and Wiman KG: Shaping genetic alterations in human cancer: The p53 mutation paradigm. Cancer Cell 12: 303-312, 2007.

11. Oliner JD, Pietenpol JA, Thiagalingam S, Gyuris J, Kinzler KW and Vogelstein B: Oncoprotein MDM2 conceals the activation domain of tumour suppressor p53. Nature 362: 857-860, 1993.

12. Ashkroft $M$ and Vousden K: Regulation of p53 stability. Oncogene 18: 7637-7643, 1999.

13. Michael D and Oren M: The p53-Mdm2 module and the ubiquitin system. Semi Cancer Biol 13: 49-58, 2003.

14. Freedman D, Wu L and Levine AJ: Functions of the MDM2 oncoprotein. Cell Mol Life Sci 5: 96-107, 1999.

15. Chène $P$, Fuchs J, Bohn J, García-Echeverría C, Furet $P$ and Fabbro D: A small synthetic peptide, which inhibits the p53-hdm2 interaction, stimulates the p53 pathway in tumour cell lines. J Mol Biol 299: 245-253, 2000.

16. Zhang RW and Wang H: Antisense oligonucleotide inhibitors of MDM2 oncogene expression. Methods Mol Med 85: 205-222, 2003.

17. Vassilev L, Vu BT, Graves B, Carvajal D, Podlaski F, Filipovic Z, Kong N, Kammlott U, Lukacs C, Klein C, et al: In vivo activation of the p53 pathway by small-molecule antagonists of MDM2. Science 303: 844-848, 2004.

18. Hu CM, Zheng LY, Pei YZ and Bai X: Synthesis of novel 3-aryl isoindolinone derivatives. Chem Res Chin Univ 29: 487-494, 2013.

19. Hu CM: Design, synthesis and anticancer activity of novel 3-aryl isoindolinone derivatives: [D]. Changchun Jilin Univ, 2012.

20. Livak KJ and Schmittgen TD: Analysis of relative gene expression data using real-time quantitative PCR and the 2(-Delta Delta C(T)) method. Methods 25: 402-408, 2001.

21. Fang $M, W u X C$ and Huang W: Raloxifene upregulated mesangial cell MMP- 2 activity via ER- $\beta$ through transcriptional regulation. Cell Biochem Biophys 67: 607-613, 2013.

22. Li MO, Sarkisian MR, Mehal WZ, Rakic P and Flavell RA Phosphatidylserine receptor is required for clearance of apoptotic cells. Science 302: 1560-1563, 2003.

23. Yin C, Knudson CM, Korsmeyer SJ and Van Dyke T: Bax suppresses tumorigenesis and stimulates apoptosis in vivo. Nature 385: 637-640, 1997
24. Miyashita T and Reed JC: Tumor suppressor p53 is a direct transcriptional activator of the human bax gene. Cell 80: 293-299, 1995.

25. Dasari S, Wudayagiri $\mathrm{R}$ and Valluru L: Cervical cancer: Biomarkers for diagnosis and treatment. Clin Chim Acta 445 7-11, 2015.

26. Canavan T and Doshi NR: Cervical cancer. Am Fam Physician 61: 1369-1376, 2000

27. Luhn P, Walker J, Schiffman M, Zuna RE, Dunn ST, Gold MA, Smith K, Mathews C, Allen RA, Zhang R, et al: The role of co-factors in the progression from human papillomavirus infection to cervical cancer. Gynecol Oncol 128: 265-270, 2013.

28. Arbyn M, Anttila A, Jordan J, Ronco G, Schenck U, Segnan N, Wiener H, Herbert A and von Karsa L: European guidelines for quality assurance in cervical cancer screening. Second edition-summary document. Ann Oncol 21: 448-458, 2010.

29. Medeiros LR, Rosa DD, da Rosa MI, Bozzetti MC and Zanini RR: Efficacy of human papillomavirus vaccines: A systematic quantitative review. Int J Gynecol Cancer 19: 1166-1176, 2009.

30. Cuzick J, Arbyn M, Sankaranarayanan R, Tsu V, Ronco G, Mayrand MH, Dillner J and Meijer CJ: Overview of human papillomavirus-based and other novel options for cervical cancer screening in developed and developing countries. Vaccine 26 (Suppl 10): k29-k41, 2008

31. Segovia-Mendoza M, Jurado R, Mir R, Medina LA, Prado-Garcia H and Garcia-Lopez P: Antihormonal agents as a strategy to improve the effect of chemo-radiation in cervical cancer: In vitro and in vivo study. BMC Cancer 15: 21, 2015.

32. Cancer Genome Atlas Research Network; Albert Einstein College of Medicine; Analytical Biological Services; Barretos Cancer Hospital; Baylor College of Medicine; Beckman Research Institute of City of Hope; Buck Institute for Research on Aging; Canada's Michael Smith Genome Sciences Centre; Harvard Medical School; Helen F. Graham Cancer Center \&Research Institute at Christiana Care Health Services, et al: Integrated genomic and molecular characterization of cervical cancer. Nature 543: 378-384, 2017.

33. Zhao Y, Aguilar A, Bernard D and Wang SM: Small-molecule inhibitors of the MDM2-p53 protein-protein interaction (MDM2 Inhibitors) in clinical trials for cancer treatment. J Med Chem 58: 1038-1052, 2015.

34. Bunz F, Dutriaux A, Lengauer C, Waldman T, Zhou S, Brown JP, Sedivy JM, Kinzler KW and Vogelstein B: Requirement for p53 and p21 to sustain G2 arrest after DNA damage. Science 282: 1497-1501, 1998.

35. Taylor RC, Cullen SP and Martin SJ: Apoptosis: Controlled demolition at the cellular level. Nat Rev Mol Cell Biol 9: 231-241, 2008.

36. Zhou BB and Elledge SJ: The DNA damage response: Putting checkpoints in perspective. Nature 408: 433-439, 2000.

37. Bucher $\mathrm{N}$ and Britten CD: G2 checkpoint abrogation and checkpoint kinase-1 targeting in the treatment of cancer. Br J Cancer 98: 523-528, 2008.

This work is licensed under a Creative Commons Attribution-NonCommercial-NoDerivatives 4.0 International (CC BY-NC-ND 4.0) License. 